\title{
The Genomic Sequence of Pseudomonas fluorescens Pf-5: Insights Into Biological Control
}

\author{
Joyce E. Loper, Donald Y. Kobayashi, and Ian T. Paulsen
}

First author: U.S. Department of Agriculture, Agricultural Research Service, Horticultural Crops Research Laboratory, Corvallis, Oregon; second author: Department of Plant Biology and Pathology, Rutgers, The State University of New Jersey, New Brunswick; and third author: The Institute for Genomic Research, Rockville, MD.

\begin{abstract}
Loper, J. E., Kobayashi, D. Y., and Paulsen, I. T. 2007. The genomic sequence of Pseudomonas fluorescens Pf-5: Insights into biological control. Phytopathology 97:233-238.

The complete sequence of the $7.07 \mathrm{Mb}$ genome of the biological control agent Pseudomonas fluorescens Pf-5 is now available, providing a new opportunity to advance knowledge of biological control through genomics. P. fluorescens $\mathrm{Pf}-5$ is a rhizosphere bacterium that suppresses seedling emergence diseases and produces a spectrum of antibiotics toxic to plant-pathogenic fungi and oomycetes. In addition to six known secondary metabolites produced by Pf-5, three novel secondary metabolite biosynthesis gene clusters identified in the genome could also contribute to biological control. The genomic sequence provides numerous

clues as to mechanisms used by the bacterium to survive in the spermosphere and rhizosphere. These features include broad catabolic and transport capabilities for utilizing seed and root exudates, an expanded collection of efflux systems for defense against environmental stress and microbial competition, and the presence of 45 outer membrane receptors that should allow for the uptake of iron from a wide array of siderophores produced by soil microorganisms. As expected for a bacterium with a large genome that lives in a rapidly changing environment, Pf-5 has an extensive collection of regulatory genes, only some of which have been characterized for their roles in regulation of secondary metabolite production or biological control. Consistent with its commensal lifestyle, Pf-5 appears to lack a number of virulence and pathogenicity factors found in plant pathogens.
\end{abstract}

Recently, the genomic sequence of the biological control agent Pseudomonas fluorescens Pf-5 was completed (47). The genomic sequence of Pf-5 is the first published for a biological control agent for plant disease. In this symposium paper, we briefly review the literature describing Pf-5, describe aspects of the genomic sequence that are particularly relevant to the capacity of Pf-5 to suppress plant disease, and provide our perspectives on how the genomic sequence data are advancing knowledge of biological control.

Plant disease suppression by $\boldsymbol{P}$. fluorescens Pf-5. Pf-5 was isolated from the cotton rhizosphere and first described for its capacity to suppress seedling diseases of cotton caused by Rhizoctonia solani (17) and Pythium ultimum (18). R. solani and Pythium ultimum are widespread pathogens with broad host ranges that constrain food and fiber production worldwide (34). The pathogens are the major causes of seed rot and seedling death of cotton and many other crop plants. Since Pf-5 was first described, it has been shown to suppress these pathogens on a variety of plant hosts including cucumber, pea, and maize (26; M. D. Henkels and J. E. Loper, unpublished data). Furthermore, Pf-5 suppresses a number of other soilborne or residue-borne fungal pathogens. For example, when inoculated onto wheat straw residue, Pf-5 suppresses ascocarp formation by the tan spot pathogen of wheat, Pyrenophora tritici-repentis, thereby decreasing inoculum available for infection of the subsequent wheat crop

Corresponding author: J. E. Loper; E-mail address: loperj@science.oregonstate.edu

DOI: 10.1094/PHYTO-97-2-0233

This article is in the public domain and not copyrightable. It may be freely reprinted with customary crediting of the source. The American Phytopathological Society, 2007
(49). On turfgrass, Pf-5 suppresses dollar spot caused by Sclerotinia homoeocarpa and leaf spot caused by Drechslera poae, which are destructive and widespread diseases affecting golf courses, home lawns, and amenity turf areas (56). Pf-5 also suppresses Fusarium crown and root rot of tomato, caused by $\mathrm{Fu}$ sarium oxysporum $\mathrm{f}$. $\mathrm{sp}$. radicis-lycopersici (61), and seed piece decay of potato caused by the bacterial pathogen Erwinia carotovora (70). Because of the wide variety of diseases it suppresses, Pf-5 is well recognized by biological control researchers around the world, and commonly is included as a reference strain in studies of biocontrol agents $(21,25,38,61,70)$.

Secondary metabolite production by Pf-5. Pf-5 produces at least seven secondary metabolites, including pyrrolnitrin (17), pyoluteorin (18), 2,4-diacetylphloroglucinol (44), hydrogen cyanide (26), the siderophores pyochelin (or related compounds) and pyoverdine, and a lipopeptide $(\mathrm{H}$. Gross, J. E. Loper, and W. Gerwick, unpublished data). In addition, two putative metabolites are assumed to exist due to the presence of biosynthetic gene clusters in the Pf-5 genome (47). Five of these secondary metabolites are known to be produced by $P$. fluorescens strain CHA0, a rhizosphere bacterium isolated in Switzerland whose biological control characteristics, mechanisms of disease suppression, and regulatory networks controlling secondary metabolite production have been extensively characterized (14). Some other biological control strains produce a subset of metabolites produced by Pf-5, and their broad spectrum antibiotic activities have been reviewed elsewhere (52).

Regulation of secondary metabolite production. Production of secondary metabolites by strains $\mathrm{CHA} 0$ or Pf- 5 is controlled by complex regulatory networks that respond to environmental and density-dependent signals and are coupled to the physiological status of the bacterium. Loci that regulate the production of anti- 
fungal metabolites in the strains include a two-component regulatory system encoded by $\operatorname{gacS}$ and $\operatorname{gacA}(9,30)$; the RNA-binding proteins RsmA and RsmE (4,54); the regulatory RNAs rsmX (20), $\operatorname{rsm} Y$ (65), and $r \operatorname{sm} Z$ (15); the sigma factors $\sigma^{\mathrm{s}}$ (58) and $\sigma^{54}$ (48); the cofactor PQQ (59); the anaerobic regulator anr (29); the translation initiation factor IF3 (3); the protease Lon (69); and ptsP, a paralog of sugar phosphotransferase enzyme I (67). Many of these loci control multiple phenotypes including stress response in $P$. fluorescens $(58,63,68,69)$, indicating that regulation of antibiotic production is intricately enmeshed in the physiology of the bacterial cell. Secondary metabolite production does not appear to be controlled by a classic quorum-sensing system based upon $N$ acyl homoserine lactones in these strains, but at least two of the antibiotics-pyoluteorin and 2,4-diacetylphloroglucinol-serve as autoinducers of their own production $(1,5,60)$.

How is Pf-5 related to other biological control strains of P. fluorescens? Biological control strains of $P$. fluorescens have been isolated from soils and plant surfaces all over the world, and they comprise a diverse group of bacteria. Nevertheless, biological control strains fall into distinct groups defined by biochemical and molecular criteria. Studies evaluating collections of biocontrol strains using these criteria consistently place Pf-5 in a group with $\mathrm{CHA} 0$ and other pyoluteorin and 2,4-diacetylphloroglucinolproducing strains (37 and references therein).

The genome of Pf-5. At $7.07 \mathrm{Mb}$, the genome of Pf-5 is the largest Pseudomonas genome sequenced to date $(7,13,19,42,64)$. It is composed of a single circular chromosome with 6,144 predicted genes (Fig. 1). Below, we provide a brief overview of the general features of the Pf-5 genome and highlight aspects of the genome of particular relevance to environmental fitness and biological control. The Pf-5 genomic sequence data discussed below have been published previously (47).

Environmental fitness. Pf-5 has the capacity to colonize seed and root surfaces, processes that involve the acquisition of diverse

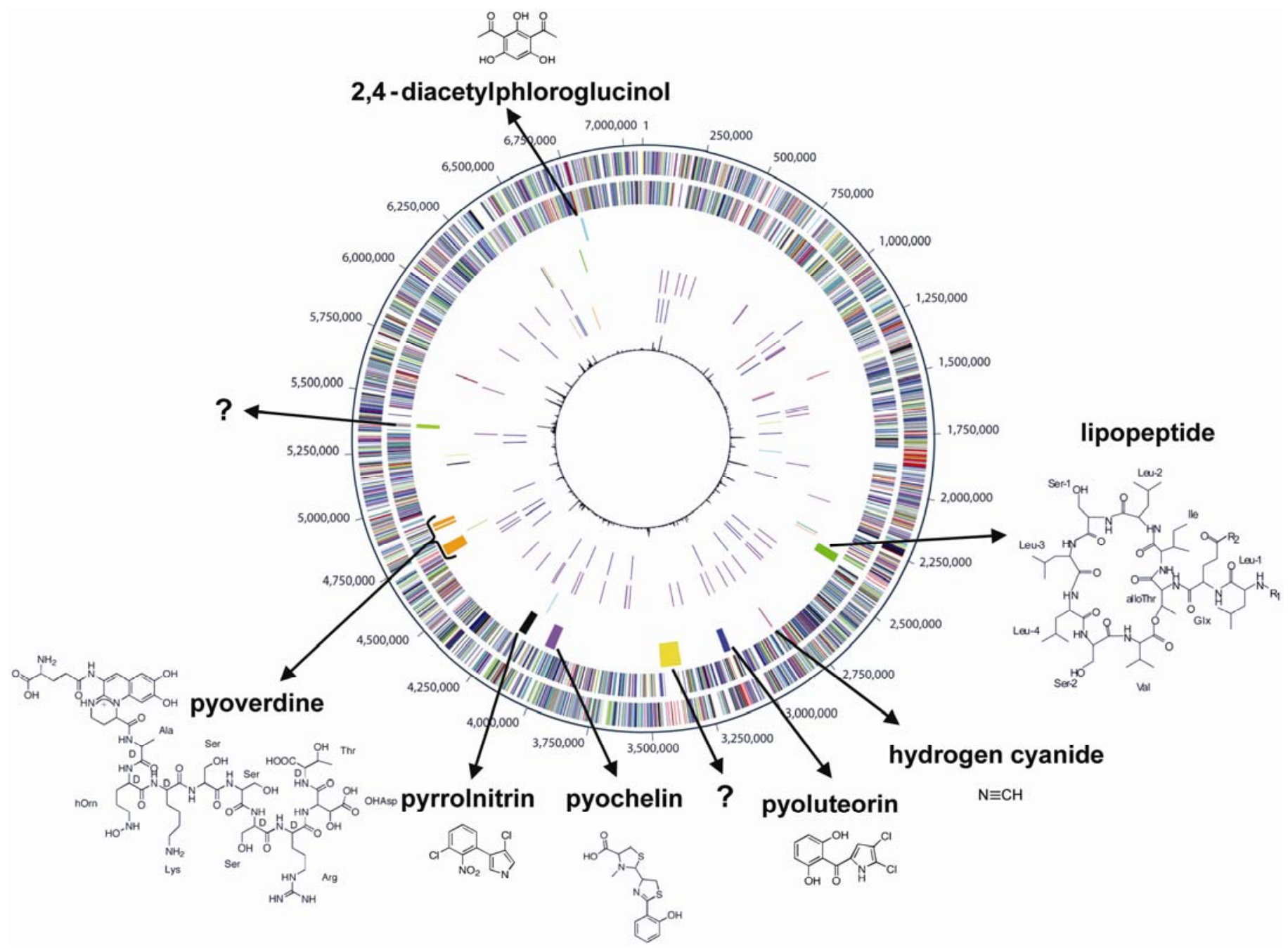

Fig. 1. Circular representation of the genome of Pseudomonas fluorescens Pf-5. The outer scale designates coordinates in base pairs, with the origin of replication at $1 \mathrm{bp}$. The first circle (outermost circle) shows predicted coding regions on the plus strand color-coded by role categories: violet, amino acid biosynthesis; light blue, biosynthesis of cofactors, prosthetic groups, and carriers; light green, cell envelope; red, cellular processes; brown, central intermediary metabolism; yellow, DNA metabolism; light gray, energy metabolism; magenta, fatty acid and phospholipid metabolism; pink, protein synthesis and fate; orange, purines, pyrimidines, nucleosides, and nucleotides; olive, regulatory functions and signal transduction; dark green, transcription; teal, transport and binding proteins; gray, unknown function; salmon, other categories; and blue, hypothetical proteins. The second circle shows predicted coding regions on the minus strand color-coded by role categories. The third circle shows nine secondary metabolite gene clusters, with the structures and names of the corresponding metabolite indicated with arrows. Gene clusters whose metabolic products are unknown are designated with a question mark. Genes in the fourth, fifth, and sixth circle are described clockwise from the origin of replication (1 bp) as follows. The fourth circle shows global regulatory genes reported to influence secondary metabolite production by Pf-5 or the related strain P. fluorescens CHA0: blue, rpoN $\left(\sigma^{54}\right)$; red, rpoS $\left(\sigma^{S}\right)$ and $r s m Z$; purple, anr; green, rsmE; salmon, infC; cyan, gacA; olive, rsmX; black, gacS; gold, $r s m A$; maroon, lon; dark gray, pqqFABC; orange, $r \operatorname{sm} Y$; and green, pts $P$. The fifth circle shows TonB-dependent outer membrane receptors in purple. The sixth circle shows sigma factors: blue, $27 \mathrm{ECF}$ sigma factors; brown, rpoN $\left(\sigma^{54}\right)$; red, rpoS $\left(\sigma^{\mathrm{S}}\right)$; gold, algT; cyan, fliA; salmon, rpoD $\left(\sigma^{70}\right)$; and orange, $r p o H\left(\sigma^{32}\right)$. The seventh circle shows trinucleotide composition in black; regions that differ markedly from the average trinucleotide composition are likely to have been recently acquired in the evolution of Pf-5. 
compounds for nutrition, attachment to surfaces, as well as defense from environmental stress and microbial competition.

Catabolism. The genomic sequence of Pf-5 specifies a broad metabolic capacity that is shared with other species of Pseudomonas (11) and is consistent with a saprophytic lifestyle in soil. The genome contains genes encoding for utilization of a broad spectrum of organic acids, sugars, and amino acids, including those typically found in seed or root exudates. Although pseudomonads are known to prefer organic acids over carbohydrates as carbon and energy sources (31), the Pf-5 genome has genes for the metabolism of a number of plant-derived carbohydrates such as maltose, sucrose, trehalose, and xylose. Also present are genes for utilization of more complex plant-derived molecules such as the aromatic compounds vanillate, benzoate, and hydroxybenzoate, as well as long chain fatty acids and hydrocarbons, of which many plant oils are comprised. Many of the Pf-5 genes that reflect a "preference" toward plant-derived compounds are shared with $P$. syringae $(7,13,19)$, and may be indicative of its association with plants.

Attachment. The Pf-5 genome contains several genes that have been implicated in the attachment of Pseudomonas spp. to surfaces, including genes encoding for predicted hemagglutinins, haemolysins, and other adhesion-related proteins. A subset of these genes is known to be involved in attachment of cells to plant surfaces. For example, Pf-5 has a full complement of genes encoding the biosynthetic pathway for alginate, an exopolysaccharide involved with bacterial attachment to plant surfaces (2), as well as genes involved in the biosynthesis of a type IV pilus, previously demonstrated to have a role in Pseudomonas attachment to leaves (57). Pf-5 also contains an aggA gene homologue encoding for an agglutinin previously described as a root attachment protein in P. putida (6). Espinosa-Urgel et al. (12) characterized several $P$. putida mutants deficient in attachment to corn seeds, which were designated mus (mutants unattached to seeds). Many of the mus loci also exist in Pf-5. These include the lapA gene encoding for a large adhesion protein associated with the mus-24 mutant (16) and the hlpBA genes encoding a two-partner secretion system associated with the mus-27 mutant (41). Pf-5 also contains other genes associated with attachment, such as the transcriptional factor $a d n A$ originally identified in $P$. fluorescens Pf0-1 $(8,10)$. AdnA mutants of Pf0-1 exhibit decreased adherence to sand and seeds, suggesting that one or more genes belonging to the $a d n A$ regulon are involved with attachment. It is apparent that several genes related to surface attachment exist in Pf-5, but their functions, especially as they pertain to plant colonization, remain unclear.

Self-defense. Compared with the genomes of $P$. aeruginosa, $P$. putida, or $P$. syringae pv. tomato, the genomic sequence of Pf-5 reveals an expanded collection of efflux systems, which typically confer protection against a range of toxic metabolites. For example, multiple drug resistance within Pseudomonas spp. has been associated, in part, with efflux systems, specifically those belonging to the resistance-nodulation-cell division (RND) superfamily (46). Within the genome of Pf-5, 13 regions contain RND homologs, with neighboring genes encoding partner proteins of the efflux systems. Other genes are predicted to confer resistance to specific toxins, including tabtoxin, a phytotoxin produced by $P$. syringae pv. tabaci, and fusaric acid, a toxin produced by the soilborne plant pathogen $F$. oxysporum that serves as a signal repressing the production of 2,4-diacetylphloroglucinol by P. fluorescens CHA0 (43).

Copper is among the chemicals used in agriculture to control plant diseases and, consequently, certain bacterial plant pathogens and soil bacteria have developed resistance to this metal. The copABCDRS cluster is responsible for copper resistance in the plant pathogen $P$. syringae pv. tomato PT23.2 (39). These genes are also present in Pf-5, but they are organized in pairs (copAB, $\operatorname{cop} C D$, and copRS) that are dispersed throughout the genome. Pf-
5 exhibits moderate levels of copper resistance, tolerating only $0.32 \mathrm{mM}$ cupric sulfate (M. D. Henkels, C. M. Press, and J. E. Loper, unpublished data), which could be related to the dispersed locations of the copper resistance genes in the Pf-5 genome. In contrast, copper-sensitive $P$. syringae DC3000, $P$. putida KT2440, and $P$. aeruginosa PAO1 have homologs of copAB but lack copCDRS $(7,42,64)$.

The capacity to detoxify active oxygen species is thought to confer a fitness advantage on Pseudomonas spp. in the rhizosphere, because mutants of $P$. putida deficient in superoxide dismutase establish smaller population sizes in the rhizosphere than does the parental strain (24). The presence of numerous copies of genes conferring tolerance to oxidative stress (i.e., 10 peroxidases, six catalases, and two superoxide dismutases) in the genome of Pf-5 supports the proposed importance of oxidative stress tolerance to the fitness of this rhizosphere bacterium.

Rhizosphere colonization. P. fluorescens Pf-5 was isolated from the cotton rhizosphere and has the capacity to establish populations of sufficient size to suppress certain soilborne pathogens on seed surfaces $(17,18)$. Nevertheless, the population size established by Pf-5 in the rhizosphere of pea or wheat is neither as large nor as persistent as populations established by the most rhizosphere competent strains of $P$. fluorescens, represented by strain Q8r1-96 $(27,28)$. In an attempt to identify genes required for rhizosphere competence, genes present in P. fluorescens Q8r196 but absent in a less rhizosphere competent strain were identified by subtractive hybridization (35). The putative rhizosphere competence genes identified in that study are not present in Pf-5. The genomic sequence of Pf-5, coupled with detailed knowledge of its biology and the biology of related strains, provides a framework for distinguishing unique genes key to the growth, persistence, and activity of plant-associated bacteria. These studies on rhizosphere competence provide an early example of the value of genomic sequence data in comparative studies of biological control bacteria.

Siderophore-mediated iron acquisition. Due to the limited availability of iron in rhizosphere and bulk soils, plant pathogens are subject to iron-competition by siderophore-producing biological control agents such as Pf-5 (32). Siderophores are highaffinity ferric-iron chelators that are exported from the cell and chelate iron in the extracellular milieu; the iron-siderophore complex is then transported into the cell via specific outer-membrane receptor proteins, thereby providing iron for cellular functions. The Pf-5 genome specifies the biosynthesis of two siderophorespyoverdine and pyochelin (or related compounds). Genes required for pyoverdine biosynthesis and uptake are organized in three gene clusters in the Pf-5 genome, a pattern shared among certain other Pseudomonas spp. (53). A putative pyochelin biosynthesis gene cluster is present in the Pf-5 genome, although its organization differs from the well-characterized pyochelin gene cluster of $P$. aeruginosa (40). Pseudomonas spp. are known to utilize siderophores produced by other microorganisms as sources of iron, and genes encoding outer membrane receptors for 20 to 30 heterologous siderophores exist in the genomes of all Pseudomonas spp. sequenced to date. Pf-5 is no exception to this, as it has 45 genes predicted to encode outer-membrane proteins that bind the transmembrane protein TonB, a characteristic of ferricsiderophore receptors (Fig. 1). Collectively, these outer membrane receptors should allow Pf-5 to utilize a wide array of siderophores produced by soil microorganisms.

It is quite possible that, when occupying natural habitats on root or soil surfaces, Pf-5 commonly acquires iron by uptake of siderophores produced by its co-inhabitants rather than relying only on the siderophores it produces. This scenario has been demonstrated for a strain of $P$. putida, which does not produce aerobactin and enterobactin but can utilize the ferric complexes of these siderophores as sources of iron. In the rhizosphere, iron availability to $P$. putida is increased in the presence of strains of 
Enterobacter cloacae that produce aerobactin and enterobactin (33), indicating that the uptake of heterologous siderophores is an important component of iron nutrition in this natural habitat. In contrast, when grown in isolation on an iron-deficient culture medium, Pseudomonas spp. must rely on siderophore production for iron nutrition. Perhaps not coincidentally, siderophoremediated iron competition between biocontrol strains of Pseudomonas spp. and their target pathogens is easily observed on an iron-deficient culture medium in the laboratory, but its occurrence is quite sporadic in natural habitats such as the rhizosphere (32). Similarly, the expression of an iron-regulated promoter in the pyoverdine biosynthesis and uptake gene cluster is higher in culture and in the rhizosphere of plants grown in sterilized soil than in nonsterilized field soil (33). These results, coupled with genomic data indicating the prevalence of siderophore uptake systems in Pseudomonas spp., suggest that these bacteria may not produce siderophores consistently on roots of field-grown plants due to the availability of readily utilized siderophores produced by other microorganisms in the environment. If this is the case, then it could explain the discrepancy observed between the role of siderophores in the interactions between Pseudomonas spp. and target pathogens on an iron-limited culture medium (where siderophores are reliably produced) versus the rhizosphere.

Secondary metabolites and other secreted products. Approximately $6 \%$ of the Pf- 5 genome is devoted to the production of secondary metabolites, based upon the sizes of the nine biosynthetic gene clusters identified to date. The nine gene clusters are distributed over a large portion of the genome (Fig. 1). As stated above, six of the gene clusters encode for the biosynthesis of compounds that were known to be produced by Pf- 5 before the genomic sequencing project was initiated. Gene clusters for three other secondary metabolites were identified in the genome of Pf-5 based upon characteristic sequences of polyketide or peptide synthases. These enzymes catalyze the formation of secondary metabolites through a nonribosomal mechanism of biosynthesis (66). Although the structures of compounds generated nonribosomally are diverse, the enzymes involved in their biosynthesis have characteristic functional domains. These domains are encoded by highly conserved sequences that can be used to identify biosynthetic gene clusters containing polyketide or peptide synthases. This approach was used to identify three gene clusters in the Pf-5 genome that presumably encode for secondary metabolites. For one peptide synthase, the amino acid sequence of the synthesized product was predicted based upon the sequence specificity of each functional domain in the enzyme for a particular amino acid in the elongating peptide chain (47). Subsequently, the structure was elucidated by purifying the compound from cultures of Pf-5 and subjecting it to chemical analysis, thereby confirming the amino acid sequence predicted using bioinformatics (H. Gross, J. E. Loper, and W. Gerwick, unpublished data). The three metabolites discovered through genomic sequencing have not yet been characterized with respect to their toxicities to plant pathogens or their roles in biological control. Nevertheless, their discovery provides new directions for research evaluating mechanisms of biological control.

In addition to secondary metabolites, Pf-5 produces other exported products, including exoenzymes and at least one bacteriocin. Many of these products, such as an extracellular alkaline protease that suppresses the root knot nematode Meloidogyne incognita (62), have been recognized characteristics of Pf-5 for many years. In contrast, bacteriocin production by Pf-5 has not been characterized until recently, when the detection of two homologs of $l l p A$ in the Pf-5 genome resulted in research demonstrating that this strain produces a bacteriocin related to LlpA (45).

Regulatory circuitry. As expected for a bacterium with a large genome that lives in a rapidly changing environment, Pf-5 has an extensive collection of regulatory genes. Among the proteobacteria whose genomes have been sequenced, Pf-5 has the largest number of sigma factors in the extracytoplasmic factor (ECF) class (22). Genes for 21 of the 27 ECF sigma factors in the Pf-5 genome are in clusters also containing genes encoding TonB-dependent outer-membrane receptors (Fig. 1). A smaller number of such gene clusters also have been reported in the genomes of other Pseudomonas spp. where, in response to a specific ferricsiderophore complex, the ECF sigma factor controls expression of the adjacent receptor gene (50). The predicted 68 histidine kinases and 113 response regulators in the Pf-5 genome also exceed the number predicted for any of the other Pseudomonas spp. whose genomic sequences are published (23). Global regulatory genes that control secondary metabolite production by Pf-5 or the related strain $\mathrm{CHA} 0$ are widely distributed in the genome of Pf-5 (Fig. 1), which is not unexpected given the broad influences of these genes on the physiology of the bacterium. It is likely that many of the regulatory genes identified through the genomic sequencing of Pf-5 will also play a role in secondary metabolite production and biological control.

Lack of key pathogenicity factors. Consistent with its commensal lifestyle, Pf-5 lacks a number of virulence factors found in plant pathogens. No evidence for a type III secretion system was found in the genomic sequence of Pf-5, although genes for these export systems have been found in other nonpathogenic strains of Pseudomonas spp. (including $P$. fluorescens) associated with plants $(36,51,55)$. There is no evidence in the Pf- 5 genome for the biosynthesis of the known $P$. syringae phytotoxins tabtoxin, syringomycin, syringotoxin, syringopeptin, or coronatine. Pf-5 lacks amylase, consistent with an inability to utilize starch, and lacks cellulases and other exoenzymes often associated with degradation of plant cell walls and cell wall components. Therefore, many genes required for pathogenicity or virulence of plant or animal pathogens do not have clear counterparts in the genome of this commensal bacterium.

Perspectives and future directions. As discussed throughout this review, bioinformatic analysis of the Pf-5 genome has led to the development of hypotheses regarding aspects of biological control that can now be further studied experimentally. Examples presented herein include the discovery of new secondary metabolites, possibly with antibiotic activities; new approaches to unravel key processes in rhizosphere colonization; and the opportunity to greatly expand our knowledge of factors regulating key biocontrol traits. Also discussed was a possible explanation for the infamous disparity between the success of biological control in a defined environment versus in a field soil, using siderophoremediated biological control as an example. Comparative genomics has already highlighted important distinctions between Pf-5 and pathogenic Pseudomonas spp. In the future, such comparisons will be invaluable in identifying genes and functions that are shared or unique to the commensal or pathogenic lifestyles of bacteria in the phytosphere. The availability of the genome sequence of Pf- 5 also opens the door to enable high throughput "hypothesis-generating" approaches to investigate biological control, such as whole genome microarrays for transcriptional profiling, proteomic approaches such as mass spectrometry-based methods for studying protein abundances and interactions, and large-scale gene knockout or heterologous expression studies. As the genomic sequences of more biological control agents become available and functional and comparative genomics of these organisms progress, we expect that genomics will become an increasingly important component of the scientific foundation underpinning the biological control of plant disease.

\section{ACKNOWLEDGMENTS}

We thank C. Press for bioinformatics support; M. Henkels for preparation of the figure; and L. Pscheidt and J. Kraus who initiated the genetic 
analysis of Pf-5 more than a decade ago (their studies laid the framework for subsequent studies of the regulation of secondary metabolite production by Pf-5 that are described in this review). This work was supported by Initiative for Future Agriculture and Food Systems grant 2001-52100-11329 from the U.S. Department of Agriculture, Cooperative State Research, Education, and Extension Service.

\section{LITERATURE CITED}

1. Baehler, E., Bottiglieri, M., Péchy-Tarr, M., Maurhofer, M., and Keel, C. 2005. Use of green fluorescent protein-based reporters to monitor balanced production of antifungal compounds in the biocontrol agent Pseudomonas fluorescens CHA0. J. Appl. Microbiol. 99:24-38.

2. Bianciotto, V., Andreotti, S., Balestrini, R., Bonfante, P., and Perotto, S. 2001. Mucoid mutants of the biocontrol strain Pseudomonas fluorescens CHA0 show increased ability in biofilm formation on mycorrhizal and nonmycorrhizal carrot roots. Mol. Plant-Microbe Interact. 14:255-260.

3. Blumer, C., and Haas, D. 2000. Multicopy suppression of a gacA mutation by the infC operon in Pseudomonas fluorescens CHA0: Competition with the global translational regulator RsmA. FEMS Microbiol. Lett. 187:53-58.

4. Blumer, C., Heeb, S., Pessi, G., and Haas, D. 1999. Global GacA-steered control of cyanide and exoprotease production in Pseudomonas fluorescens involves specific ribosome binding sites. Proc. Natl. Acad. Sci. USA 96:14073-14078

5. Brodhagen, M., Henkels, M. D., and Loper, J. E. 2004. Positive autoregulation of the antibiotic pyoluteorin in the biological control organism Pseudomonas fluorescens Pf-5. Appl. Environ. Microbiol. 70:1758-1766.

6. Buell, C. R., and Anderson, A. J. 1992. Genetic analysis of the aggA locus involved in agglutination and adherence of Pseudomonas putida, a beneficial fluorescent Pseudomonad. Mol. Plant-Microbe Interact. 5:154162.

7. Buell, C. R., Joardar, V., Lindeberg, M., Selengut, J., Paulsen, I. T., Gwinn, M. L., Dodson, R. J., Deboy, R. T., Durkin, A. S., Kolonay, J. F., Madupu, R., Daugherty, S., Brinkac, L., Beanan, M. J., Haft, D. H., Nelson, W. C., Davidsen, T., Zafar, N., Zhou, L., Liu, J., Yuan, Q., Khouri, H., Fedorova, N., Tran, B., Russell, D., Berry, K., Utterback, T., Van Aken, S. E., Feldblyum, T. V., D’Ascenzo, M., Deng, W. L., Ramos, A. R., Alfano, J. R., Cartinhour, S., Chatterjee, A. K., Delaney, T. P., Lazarowitz, S. G., Martin, G. B., Schneider, D. J., Tang, X., Bender, C. L., White, O., Fraser, C. M., and Collmer, A. 2003. The complete genome sequence of the Arabidopsis and tomato pathogen Pseudomonas syringae pv. tomato DC3000. Proc. Natl. Acad. Sci. USA 100:10181-10186.

8. Casaz, P., Happel, A., Keithan, J., Read, D. L., Strain, S. R., and Levy, S. B. 2001. The Pseudomonas fluorescens transcription activator AdnA is required for adhesion and motility. Microbiology 147:355-361.

9. Corbell, N., and Loper, J. E. 1995. A global regulator of secondary metabolite production in Pseudomonas fluorescens Pf-5. J. Bacteriol. 177:6230-6236.

10. DeFlaun, M., Marshall, B., Kulle, E., and Levy, S. 1994. Tn5 insertion mutants of Pseudomonas fluorescens defective in adhesion to soil and seeds. Appl. Environ. Microbiol. 60:2637-2642.

11. dos Santos, V. A. P. M., Heim, S., Moore, E. R. B., Strätz, M., and Timmis, K. N. 2004. Insights into the genomic basis of niche specificity of Pseudomonas putida KT2440. Environ. Microbiol. 6:1264-1286.

12. Espinosa-Urgel, M., Salido, A., and Ramos, J.-L. 2000. Genetic analysis of functions involved in adhesion of Pseudomonas putida to seeds. J. Bacteriol. 182:2363-2369.

13. Feil, H., Feil, W. S., Chain, P., Larimer, F., DiBartolo, G., Copeland, A., Lykidis, A., Trong, S., Nolan, M., Goltsman, E., Thiel, J., Malfatti, S., Loper, J. E., Lapidus, A., Detter, J. C., Land, M., Richardson, P. M., Kyrpides, N. C., Ivanova, N., and Lindow, S. E. 2005. Comparison of the complete genome sequences of Pseudomonas syringae pv. syringae $\mathrm{B} 728 \mathrm{a}$ and pv. tomato DC3000. Proc. Natl. Acad. Sci. USA 102:11064-11069.

14. Haas, D., and Keel, C. 2003. Regulation of antibiotic production in rootcolonizing Pseudomonas spp. and relevance for biological control of plant disease. Annu. Rev. Phytopathol. 41:117-153.

15. Heeb, S., Blumer, C., and Haas, D. 2002. Regulatory RNA as mediator in $\mathrm{GacA} /$ RsmA-dependent global control of exoproduct formation in Pseudomonas fluorescens CHA0. J. Bacteriol. 184:1046-1056.

16. Hinsa, S. M., Espinosa-Urgel, M., Ramos, J. L., and O’Toole, G. A. 2003. Transition from reversible to irreversible attachment during biofilm formation by Pseudomonas fluorescens WCS365 requires an ABC transporter and a large secreted protein. Mol. Microbiol. 49:905-918.

17. Howell, C. R., and Stipanovic, R. D. 1979. Control of Rhizoctonia solani in cotton seedlings with Pseudomonas fluorescens and with an antibiotic produced by the bacterium. Phytopathology 69:480-482.

18. Howell, C. R., and Stipanovic, R. D. 1980. Suppression of Pythium ultimum induced damping-off of cotton seedlings by Pseudomonas fluorescens and its antibiotic pyoluteorin. Phytopathology 70:712-715.

19. Joardar, V., Lindeberg, M., Jackson, R. W., Selengut, J., Dodson, R., Brinkac, L. M., Daugherty, S. C., Deboy, R., Durkin, A. S., Giglio, M. G., Madupu, R., Nelson, W. C., Rosovitz, M. J., Sullivan, S., Crabtree, J., Creasy, T., Davidsen, T., Haft, D. H., Zafar, N., Zhou, L., Halpin, R., Holley, T., Khouri, H., Feldblyum, T., White, O., Fraser, C. M., Chatterjee, A. K., Cartinhour, S., Schneider, D. J., Mansfield, J., Collmer, A., and Buell, C. R. 2005. Whole-genome sequence analysis of Pseudomonas syringae pv. phaseolicola 1448A reveals divergence among pathovars in genes involved in virulence and transposition. J. Bacteriol. 187:6488-6498.

20. Kay, E., Dubuis, C., and Haas, D. 2005. Three small RNAs jointly ensure secondary metabolism and biocontrol in Pseudomonas fluorescens CHA0. Proc. Natl. Acad. Sci. USA 102:17136-17141.

21. Keel, C., Weller, D. M., Natsch, A., Defago, G., Cook, R. J., and Thomashow, L. S. 1996. Conservation of the 2,4-diacetylphloroglucinol biosynthesis locus among fluorescent Pseudomonas strains from diverse geographic locations. Appl. Environ. Microbiol. 62:552-563.

22. Kiil, K., Binnewies, T. T., Sicheritz-Pontén, T., Willenbrock, H., Hallin, P. F., Wassenaar, P. F., and Ussery, D. W. 2005. Genome update: Sigma factors in 240 bacterial genomes. Microbiology 151:3147-3150.

23. Kiil, K., Ferchaud, J. P., David, C., Binnewies, T. T., Wu, H., SicheritzPontén, T., Willenbrock, H., and Ussery, D. W. 2005. Genome update: Distribution of two-component transduction systems in 250 bacterial genomes. Microbiology 151:3447-3452.

24. Kim, Y. C., Miller, C. D., and Anderson, A. J. 2000. Superoxide dismutase activity in Pseudomonas putida affects utilization of sugars and growth on root surfaces. Appl. Environ. Microbiol. 66:1460-1467.

25. Kloepper, J. W. 1991. Development of in vivo assays for prescreening antagonists of Rhizoctonia solani on cotton. Phytopathology 81:10061013.

26. Kraus, J., and Loper, J. E. 1992. Lack of evidence for a role of antifungal metabolite production by Pseudomonas fluorescens Pf-5 in biological control of Pythium damping-off of cucumber. Phytopathology 82:264271.

27. Landa, B. B., Mavrodi, D. M., Thomashow, L. S., and Weller, D. M. 2003. Interactions between strains of 2,4-diacetylphloroglucinol-producing Pseudomonas fluorescens in the rhizosphere of wheat. Phytopathology 93:982-994

28. Landa, B. B., Mavrodi, O. V., Raaijmakers, J. M., McSpadden Gardener, B. B., Thomashow, L. S., and Weller, D. M. 2002. Differential ability of genotypes of 2,4-diacetylphloroglucinol-producing Pseudomonas fluorescens strains to colonize the roots of pea plants. Appl. Environ. Microbiol. 68:3226-3237

29. Laville, J., Blumer, C., Von Schroetter, C., Gaia, V., Defago, G., Keel, C., and Haas, D. 1998. Characterization of the $h c n A B C$ gene cluster encoding hydrogen cyanide synthase and anaerobic regulation by ANR in the strictly aerobic biocontrol agent Pseudomonas fluorescens CHA0. J. Bacteriol. 180:3187-3196.

30. Laville, J., Voisard, C., Keel, C., Maurhofer, M., Defago, G., and Haas, D. 1992. Global control in Pseudomonas fluorescens mediating antibiotic synthesis and suppression of black root rot of tobacco. Proc. Natl. Acad. Sci. USA 89:1562-1566.

31. Lessie, T. G., and Phibbs, P. V., Jr. 1984. Alternative pathways of carbohydrate utilization in pseudomonads. Annu. Rev. Microbiol. 38:359-387.

32. Loper, J. E., and Buyer, J. S. 1991. Siderophores in microbial interactions on plant surfaces. Mol. Plant-Microbe Interact. 4:5-13.

33. Loper, J. E., and Henkels, M. D. 1999. Utilization of heterologous siderophores enhances levels of iron available to Pseudomonas putida in the rhizosphere. Appl. Environ. Microbiol. 65:5357-5363.

34. Martin, F. N., and Loper, J. E. 1999. Soilborne plant diseases caused by Pythium spp.: Ecology, epidemiology, and prospects for biological control. Crit. Rev. Plant Sci. 18:111-181.

35. Mavrodi, D. V., Mavrodi, O. V., McSpadden-Gardener, B. B., Landa, B. B., Weller, D. M., and Thomashow, L. S. 2002. Identification of differences in genome content among phlD-positive Pseudomonas fluorescens strains by using PCR-based subtractive hybridization. Appl. Environ. Microbiol. 68:5170-5176.

36. Mazurier, S., Lemunier, M., Siblot, S., Mougel, C., and Lemanceau, P. 2004. Distribution and diversity of type III secretion system-like genes in saprophytic and phytopathogenic fluorescent pseudomonads. FEMS (Fed. Eur. Microbiol. Soc.) Microbiol. Ecol. 49:455-467.

37. McSpadden-Gardener, B. B., Gutierrez, L. J., Joshi, R., Edema, R., and Lutton, E. 2005. Distribution and biocontrol potential of phlD(+) pseudomonads in corn and soybean fields. Phytopathology 95:715-724.

38. McSpadden-Gardener, B. B., Schroeder, K. L., Kalloger, S. E., Raaijmakers, J. M., Thomashow, L. S., and Weller, D. M. 2000. Genotypic and phenotypic diversity of phlD-containing Pseudomonas strains isolated from the rhizosphere of wheat. Appl. Environ. Microbiol. 66:1939-1946 
39. Mellano, M. A., and Cooksey, D. A. 1998. Nucleotide sequence and organization of copper resistance genes from Pseudomonas syringae pv. tomato. J. Bacteriol. 170:2879-2883.

40. Michel, L., Gonzalez, N., Jagdeep, S., Nguyen-Ngoc, T., and Reimmann, C. 2005. PchR-box recognition by the AraC-type regulator PchR of Pseudomonas aeruginosa requires the siderophore pyochelin as an effector. Mol. Microbiol. 58:495-509.

41. Molina, M. A., Ramos, J.-L., and Espinosa-Urgel, M. 2006. A two-partner secretion system is involved in seed and root uptake colonization and iron uptake by Pseudomonas putida KT2440. Environ. Microbiol. 8:639-647.

42. Nelson, K. E., Weinel, C., Paulsen, I. T., Dodson, R. J., Hilbert, H., Martins dos Santos, V. A., Fouts, D. E., Gill, S. R., Pop, M., Holmes, M., Brinkac, L., Beanan, M., DeBoy, R. T., Daugherty, S., Kolonay, J., Madupu, R., Nelson, W., White, O., Peterson, J., Khouri, H., Hance, I., Chris Lee, P., Holtzapple, E., Scanlan, D., Tran, K., Moazzez, A., Utterback, T., Rizzo, M., Lee, K., Kosack, D., Moestl, D., Wedler, H., Lauber, J., Stjepandic, D., Hoheisel, J., Straetz, M., Heim, S., Kiewitz, C., Eisen, J. A., Timmis, K. N., Dusterhoft, A., Tummler, B., and Fraser, C. M. 2002. Complete genome sequence and comparative analysis of the metabolically versatile Pseudomonas putida KT2440. Environ. Microbiol. 4:799-808.

43. Notz, R., Maurhofer, M., Dubach, H., Haas, D., and Defago, G. 2002. Fusaric acid-producing strains of Fusarium oxysporum alter 2,4-diacetylphloroglucinol biosynthetic gene expression in Pseudomonas fluorescens CHA0 in vitro and in the rhizosphere of wheat. Appl. Environ. Microbiol. 68:2229-2235.

44. Nowak-Thompson, B., Gould, S. J., Kraus, J., and Loper, J. E. 1994. Production of 2,4-diacetylphloroglucinol by the biological control agent Pseudomonas fluorescens Pf-5. Can. J. Microbiol. 40:1064-1066.

45. Parret, A. H., Temmerman, K., and De Mot, R. 2005. Novel lectin-like bacteriocins of biocontrol strain Pseudomonas fluorescens Pf-5. Appl. Environ. Microbiol. 71:5197-5207.

46. Paulsen, I. T., Brown, M. H., and Skurray, R. A. 1996. Proton-dependent multidrug efflux systems. Microbiol. Rev. 60:575-608.

47. Paulsen, I. T., Press, C. M., Ravel, J., Kobayashi, D. Y., Myers, G. S. A., Mavrodi, D. V., DeBoy, R. T., Seshadri, R., Ren, Q., Madupu, R., Dodson, R. J., Durkin, A. S., Brinkac, L. M., Daugherty, S. C., Sullivan, S. A., Rosovitz, M. J., Gwinn, M. L., Zhou, L., Schneider, D. J., Cartinhour, S. W., Nelson, W. C., Weidman, J., Watkins, K., Tran, K., Khouri, H., Pierson, E. A., Pierson, L. S., III, Thomashow, L. S., and Loper, J. E. 2005. Complete genome sequence of the plant commensal Pseudomonas fluorescens Pf-5. Nature Biotechnol. 23:873-878.

48. Péchy-Tarr, M., Bottiglieri, M., Mathys, S., Lejbølle, K. B., SchniderKeel, U., Maurhofer, M., and Keel, C. 2005. RpoN $\left(\sigma^{54}\right)$ controls production of antifungal compounds and biocontrol activity in Pseudomonas fluorescens CHA0. Mol. Plant-Microbe Interact. 18:260-272.

49. Pfender, W. F., Kraus, J., and Loper, J. E. 1993. A genomic region from Pseudomonas fluorescens Pf-5 required for pyrrolnitrin production and inhibition of Pyrenophora tritici-repentis in wheat straw. Phytopathology 83:1223-1228.

50. Poole, K., and McKay, G. A. 2003. Iron acquisition and its control in Pseudomonas aeruginosa: Many roads lead to Rome. Front. Biosci. 8:661-686.

51. Preston, G. M., Bertrand, N., and Rainey, P. 2001. Type III secretion in plant growth-promoting Pseudomonas fluorescens SBW25. Mol. Microbiol. 41:999-1014.

52. Raaijmakers, J. M., Vlami, M., and de Souza, J. T. 2002. Antibiotic production by bacterial biocontrol agents. Antonie Van Leeuwenhoek 81:537-547.

53. Ravel, J., and Cornelis, P. 2003. Genomics of pyoverdine-mediated iron uptake in pseudomonads. Trends Microbiol. 11:195-200.

54. Reimmann, C., Valverde, C., Kay, E., and Haas, D. 2005. Posttranscriptional repression of $\mathrm{GacS} / \mathrm{GacA}$-controlled genes by the RNA-binding protein RsmE acting together with RsmA in the biocontrol strain Pseudomonas fluorescens CHA0. J. Bacteriol. 187:276-285.
55. Rezzonico, F., Binder, C., Defago, G., and Moenne-Loccoz, Y. 2005. The type III secretion system of biocontrol Pseudomonas fluorescens KD targets the phytopathogenic Chromista Pythium ultimum and promotes cucumber protection. Mol. Plant-Microbe Interact. 18:991-1001.

56. Rodriguez, F., and Pfender, W. F. 1997. Antibiosis and antagonism of Sclerotinia homoeocarpa and Drechslera poae by Pseudomonas fluorescens Pf-5 in vitro and in planta. Phytopathology 87:614-621.

57. Roine, E., Raineri, D. M., Romantscuk, M., Wilson, M., and Nunn, D. N. 1998. Characterization of Type IV pilus genes in Pseudomonas syringae pv. tomato DC3000. Mol. Plant-Microbe Interact. 11:1048-1056.

58. Sarniguet, A., Kraus, J., Henkels, M. D., Muehlchen, A. M., and Loper, J. E. 1995. The sigma factor RpoS affects antibiotic production and biological control activity of Pseudomonas fluorescens Pf-5. Proc. Natl. Acad. Sci. USA 92:12255-12259.

59. Schnider, U., Keel, C., Voisard, C., Défago, G., and Haas, D. 1995. Tn5directed cloning of $p q q$ genes from Pseudomonas fluorescens CHA0: Mutational inactivation of the genes results in overproduction in the antibiotic pyoluteorin. Appl. Environ. Microbiol. 61:3856-3864.

60. Schnider-Keel, U., Seematter, A., Maurhofer, M., Blumer, C., Duffy, B., Gigot-Bonnefoy, C., Reimmann, C., Notz, R., Defago, G., Haas, D., and Keel, C. 2000. Autoinduction of 2,4-diacetylphloroglucinol biosynthesis in the biocontrol agent Pseudomonas fluorescens CHA0 and repression by the bacterial metabolites salicylate and pyoluteorin. J. Bacteriol. 182:1215-1225.

61. Sharifi-Tehrani, A., Zala, M., Natsch, A., Moenne-Loccoz, Y., and Defago, G. 1998. Biocontrol of soil-borne fungal plant diseases by 2,4diacetylphloroglucinol-producing fluorescent pseudomonads with different restriction profiles of amplified 16S rDNA. Eur. J. Plant Pathol. 104: 631-643.

62. Siddiqui, I. A., Haas, D., and Heeb, S. 2005. Extracellular protease of Pseudomonas fluorescens $\mathrm{CHA}$, a biocontrol factor with activity against the root-knot nematode Meloidogyne incognita. Appl. Environ. Microbiol. 71:5646-5649.

63. Stockwell, V. O., and Loper, J. E. 2005. The sigma factor RpoS is required for stress tolerance and environmental fitness of Pseudomonas fluorescens Pf-5. Microbiology 151:3001-3009.

64. Stover, C. K., Pham, X. Q., Erwin, A. L., Mizoguchi, S. D., Warrener, P., Hickey, M. J., Brinkman, F. S., Hufnagle, W. O., Kowalik, D. J., Lagrou, M., Garber, R. L., Goltry, L., Tolentino, E., Westbrock-Wadman, S., Yuan, Y., Brody, L. L., Coulter, S. N., Folger, K. R., Kas, A., Larbig, K., Lim, R., Smith, K., Spencer, D., Wong, G. K., Wu, Z., Paulsen, I. T., Reizer, J., Saier, M. H., Hancock, R. E., Lory, S., and Olson, M. V. 2000. Complete genome sequence of Pseudomonas aeruginosa PA01, an opportunistic pathogen. Nature 406:959-964.

65. Valverde, C., Heeb, S., Keel, C., and Haas, D. 2003. RsmY, a small regulatory RNA, is required in concert with $\mathrm{RsmZ}$ for GacA-dependent expression of biocontrol traits in Pseudomonas fluorescens CHA0. Mol. Microbiol. 50:1361-1379.

66. Wenzel, S. C., and Muller, R. 2005. Formation of novel secondary metabolites by bacterial multimodular assembly lines: Deviations from textbook biosynthetic logic. Curr. Opin. Chem. Biol. 9:447-458.

67. Whistler, C. A. 2000. Regulation of antibiotic production and stress response by the biological control organism Pseudomonas fluorescens Pf5. Ph.D. diss. Oregon State University.

68. Whistler, C. A., Corbell, N. A., Sarniguet, A., Ream, W., and Loper, J. E. 1998. The two-component regulators GacS and GacA influence accumulation of the stationary-phase sigma factor RpoS and the stress response in Pseudomonas fluorescens Pf-5. J. Bacteriol. 180:6635-6641.

69. Whistler, C. A., Stockwell, V. O., and Loper, J. E. 2000. Lon protease influences antibiotic production and ultraviolet tolerance of Pseudomonas fluorescens Pf-5. Appl. Environ. Microbiol. 66:2718-2725.

70. Xu, G. W., and Gross, D. C. 1986. Selection of fluorescent pseudomonads antagonistic to Erwinia carotovora and suppressive of potato seed piece decay. Phytopathology 76:414-422. 